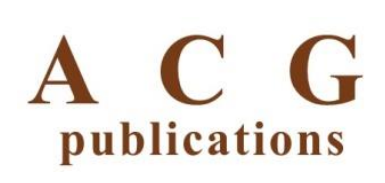

Org. Commun. 12:4 (2019) 222-226

organic communications

\title{
One-step transformation of a fluoro-based polymer into a superhydrophobic polymer composite
}

\author{
Mehtap Evci ${ }^{1}$ and Tuncer Caykara ${ }^{2^{*}}$ \\ ${ }^{I}$ Department of Chemistry, Faculty of Art and Science, Hitit University, Türkiye \\ ${ }^{2}$ Department of Chemistry, Faculty of Science, Gazi University, 06500 Besevler, Ankara Türkiye
}

(Received September 10, 2019; Revised October 25, 2019 ; Accepted October 26, 2019)

\begin{abstract}
We describe the formation of superhydrophobic surfaces by controlling the surface roughness using some simple processing methods, such as annealing at $120^{\circ} \mathrm{C}$, freeze-drying at $-40{ }^{\circ} \mathrm{C}$ and composite film preparation. The root-mean-square (rms) roughness and the water contact angle values of untreated poly $(3,3,4,4,5,5,6,6,7,7,8,8,9,9,10,10,11,11,12,12$-heneicosaffluorododecyl acrylate) (PHFDA) film prepared on silicon substrate using spin-coating technique were about $1.35 \mathrm{~nm}$ and $\theta_{A} / \theta_{R}=125^{\circ} / 103^{\circ}$, respectively. On the other hand, the annealed film $\mathrm{C}$ and the freeze-dried film with only a small increase in the rms roughness and the water contact angle values were $2.05 \mathrm{~nm}$ and $\theta_{\mathrm{A}} / \theta_{\mathrm{R}}=126^{\circ} / 111^{\circ}$, and $2.28 \mathrm{~nm}$ and $\theta_{\mathrm{A}} / \theta_{\mathrm{R}}=130^{\circ} / 123^{\circ}$, respectively. However, these values for the composite film composed of PHFDA and active carbon were $2.54 \mathrm{~nm}$ and $\theta_{\mathrm{A}} / \theta_{\mathrm{R}}=$ $165^{\circ} / 164^{\circ}$, respectively. This method can be applied to various surfaces as long as the composites composed of nanoparticles and polymeric materials do not cause any aggregation in spin-coating.
\end{abstract}

Keywords: Superhydrophobic surfaces; surface roughness; composite film; active carbon; spin-coating. (C) 2019 ACG Publications. All rights reserved.

\section{Introduction}

Superhydrophobic surfaces are usually obtained by controlling the surface chemistry and surface roughness of the polymer materials using various methods. The water contact angles of polymers having long-chain hydrocarbon or fluorocarbon chains are in the range from $110^{\circ}$ to $120^{\circ}$ [3-7]. The hydrophobicity of a surface can be increased by the grafting of fluorocarbon groups. However, the water contact angle on the smooth hydrophobic surface generally does not exceed $125^{\circ}[8,9]$. Nowadays, studies involving the preparation of superhydrophobic surfaces (lignocellulose nanofibrils [10], stainless steel [11], wood [12]... etc) suitable for the purpose of use are quite attractive. Superhydrophobic surfaces $\left(>150^{\circ}\right.$ ) can be obtained by controlling the surface roughness via various processing methods, such as etching [13, 14], drop evaporation [15], a gel-like porous coating [16] and spin-coating of nanoparticles dispersed in an organic solvent onto polymeric films [17]. However, the preparation of these surfaces often goes through the complex time-consuming processes. In this study, the superhydrophobic surfaces were prepared using some simple processing methods such as annealing at $120^{\circ} \mathrm{C}$, freeze drying at -40 ${ }^{\circ} \mathrm{C}$, and composite films composed of PHFDA and active carbon.

\footnotetext{
* Corresponding author: E-mail: caykara@gazi.edu.tr

The article was published by ACG Publications 


\section{Background}

Surface wettability is controlled by the combination of surface roughness and materials with low surface energy. In nature, the unusual superhydrophobicity of lotus plants having water contact angles larger than $150^{\circ}$ is known to result from surface roughness and surface chemistry $[1,2]$. PHFDA is a hydrophobic polymer (it has a water contact angle of $\sim 125^{\circ} \mathrm{C}$ ) and its hydrophobicity can be enhanced using various processes.

\section{Experimental}

PHFDA was synthesized by the reversible addition-fragmentation chain transfer (RAFT) polymerization using HFDA monomer, 4,4'-azobis(4-cyanovaleric acid) (ACVA) initiator and 2-cyano-2-propyl benzodithioate RAFT agent in anhydrous 1,4-dioxan at $90{ }^{\circ} \mathrm{C}$ for $4 \mathrm{~h}$. The synthesized polymer was dissolved in tetrahydrofurane (THF) and precipitated in $n$-hexane and dried at $40{ }^{\circ} \mathrm{C}$ under vacuum. After dissolving the polymer in THF $(1.0 \%$, w/v) and spin-coating at $3000 \mathrm{rpm}$ for $1 \mathrm{~min}$, we obtained a smooth film on the silicon substrate. This polymer film was called as the untreated film. Meanwhile, using untreated films, annealing, freeze-drying and composite films were prepared by annealing at $120{ }^{\circ} \mathrm{C}$, freeze-drying at $-40{ }^{\circ} \mathrm{C}$, and composite creation processes, respectively. The morphology images of the surfaces were stored using a Multimode Atomic Force Microscope (AFM) (Park Systems XE70 SPM Controller LSF-100 HS) as topographical scans in non-tapping mode in air at a scan rate of $1 \mathrm{~Hz}$. The X-ray photoelectron spectroscopy (XPS) measurements were performed on a SPECS XPS spectrometer supplied by an $\mathrm{Mg} \mathrm{K} \alpha$ X-ray source. All the spectra were calibrated in accordance with the aliphatic $\mathrm{C} 1 \mathrm{~s}$ component at a binding energy of $285.0 \mathrm{eV}$, following peak fitting of the $\mathrm{C} 1 \mathrm{~s}$ spectra. The water contact angle measurements were carried out at room temperature employing a DSA 100, Krüss type goniometer, which is supplied by a microliter syringe.

\section{Present Study}

PHFDA was synthesized by the RAFT polymerization (Scheme 1).
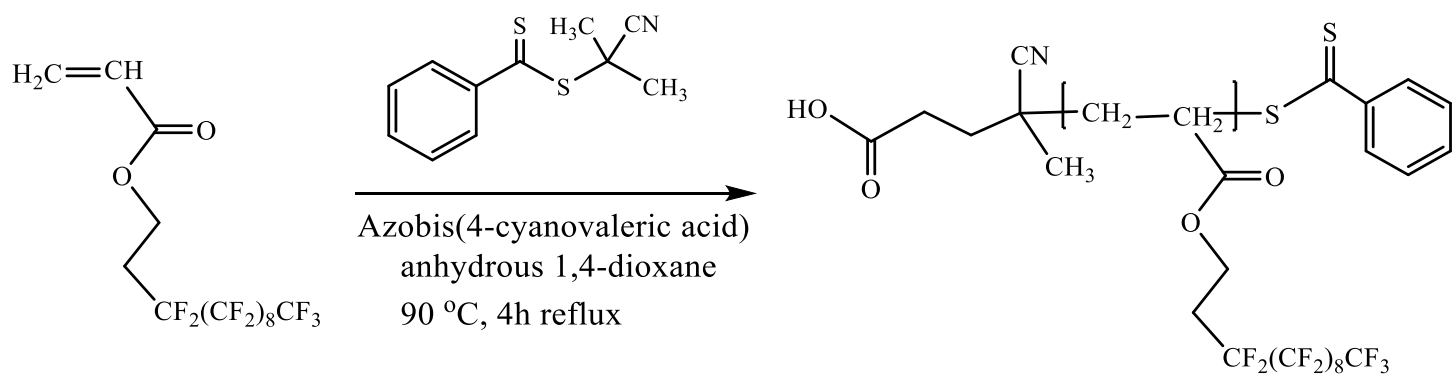

PHFDA

Scheme 1. Synthesis of PHFDA via RAFT polymerization.

The theoretical molecular weight, $\mathrm{M}_{\mathrm{n}, \mathrm{th}}$ of PHFDA was calculated as $15800 \mathrm{~g} \mathrm{~mol}^{-1}$ using $\mathrm{M}_{\mathrm{n}, \mathrm{th}}=$ $[\mathrm{M}]_{\mathrm{o}} /\left([\mathrm{RAFT}]_{\mathrm{o}}+[\mathrm{ACVA}]_{\mathrm{o}}\right) \times \mathrm{M}_{\mathrm{M}} \times$ Conversion, where $[\mathrm{M}]_{\mathrm{o}},[\mathrm{RAFT}]_{\mathrm{o}}$ and $[\mathrm{ACVA}]_{\mathrm{o}}$ are the initial concentration of HFDA, RAFT agent and ACVA, respectively. $M_{M}$ is the molecular weight of HFDA. Absolute molecular weight, $\mathrm{M}_{\mathrm{n}, \mathrm{NMR}}$ was determined as $28000 \mathrm{~g} \mathrm{~mol}^{-1}$ by ${ }^{1} \mathrm{H}$ NMR measurements [18], $\mathrm{M}_{\mathrm{n}, \mathrm{NMR}}=\left[\left(\mathrm{I}^{1.92}+\mathrm{I}^{4.92}\right) / 4\right] /\left(\mathrm{I}^{7.90-7.50} / 5\right) \times \mathrm{M}_{\mathrm{M}}+\mathrm{M}_{\mathrm{RAFT}}$ correspond to integrals of peak signals at $\delta 1.87 \mathrm{ppm}$, $4.06 \mathrm{ppm}$ and $\delta 7.30-7.42 \mathrm{ppm}$ attributed to the $\mathrm{CH}_{2}$ groups of PHFDA and the phenyl group of RAFT agent, respectively (Figure S1). The elemental composition of the untreated film was verified by survey scan XPS, where the peaks ascribed to C, O, and F are clearly observed (Figure 1a). 


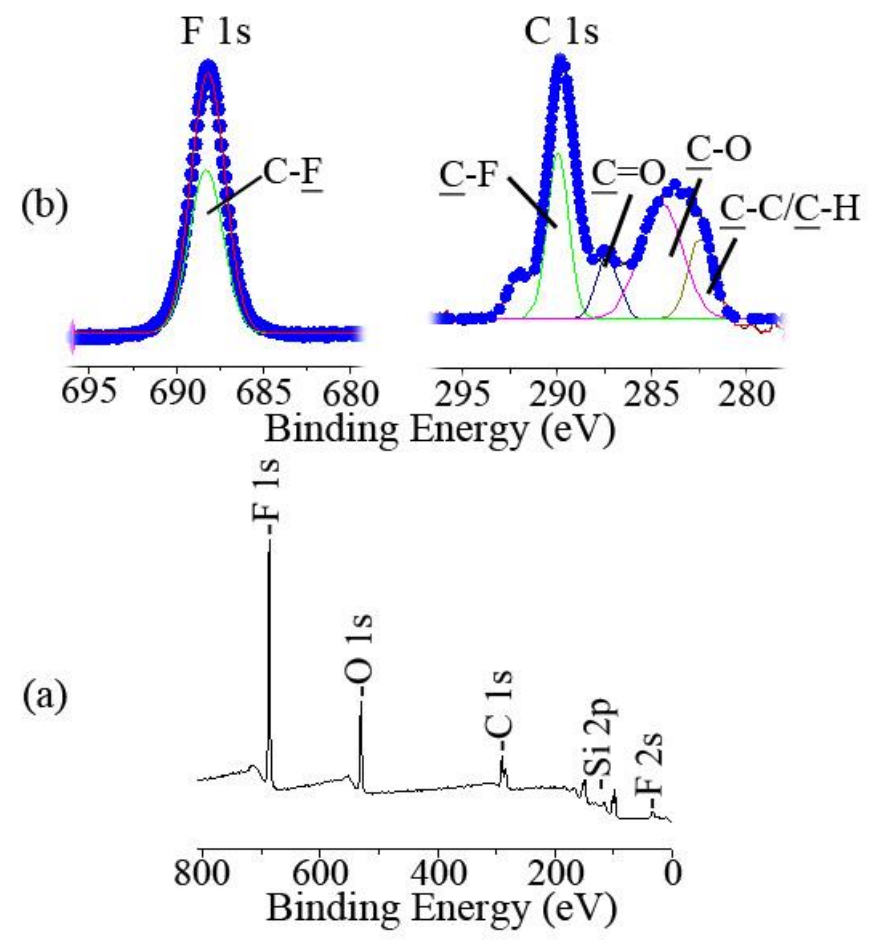

Figure 1. XPS (a) survey scan, (b) C1s and F1s core-level spectra of the PHFDA films

The presence of the Si signals in the survey scan XPS spectrum of the PHFDA film indicates that the thickness of the polymer film is below the probing depth of the XPS technique (thickness $=9.5 \mathrm{~nm}$ ) [19]. The XPS C1s spectrum of the film was deconvoluted into three peak components having binding energies at about 282.3, 284.8, 287.5 and $290.2 \mathrm{eV}$, attributable to the $\mathrm{C}-\mathrm{C} / \mathrm{C}-\mathrm{H}, \mathrm{C}=\mathrm{O}, \mathrm{C}-\mathrm{O}$ and C-F species, respectively (Figure 1b). The experimental $\mathrm{F} / \mathrm{C}$ ratio of 1.30 is different from that of the theoretical ratio of 1.24 in a single monomeric unit of the PHFDA, indicating that the $-\mathrm{CF}_{3}$ groups with low-energy are enriched on the surface and the partial surface roughness is formed. The surface roughness was controlled with atomic force microscopy (AFM) and had rms roughness of $1.35 \mathrm{~nm}$ (Figure 2a).

The shape of the water drop on the resulting PHFDA film has high advancing/receding contact angles of $\theta_{\mathrm{A}} / \theta_{\mathrm{R}}=125^{\circ} / 103^{\circ}$ due to a mostly vertical orientation of the fluoroalkyl groups in PHFDA relative to the substrate $\left(-\mathrm{CF}_{3}\right.$ outer side) [20] (Figure 2a). To compare the water contact angle of the untreated film, after spin-coating, two different films were prepared by annealing at $120{ }^{\circ} \mathrm{C}$ for 2 $\mathrm{h}$ and by freeze-drying at $-40{ }^{\circ} \mathrm{C}$, respectively. The rms roughness of the annealed and the freezedried films were about 2.05 and $2.28 \mathrm{~nm}$, respectively (Figures $2 \mathrm{~b}$ and $2 \mathrm{c}$ ). Partial surface roughness may occur due to the removal of physisorbed solvent in the polymer film during the freeze-drying process at $40^{\circ} \mathrm{C}$. Their water contact angle values were $\theta_{\mathrm{A}} / \theta_{\mathrm{R}}=126^{\circ} / 111^{\circ}$ and $\theta_{\mathrm{A}} / \theta_{\mathrm{R}}=130^{\circ} / 123^{\circ}$, respectively, but still insufficient to be classified as superhydrophobic. Therefore, we prepared the composite film composed of PHFDA and active carbon for forming superhydrophobic coating on the silicon substrate. Thus, we improved the water contact angle values from $\theta_{A} / \theta_{R}=130^{\circ} / 123^{\circ}$ to $\theta_{A} / \theta_{R}=165^{\circ} / 164^{\circ}$ (Figure $2 \mathrm{~d})$. Moreover, this film exhibited a very small contact angle hysteresis $\left(\sim 1^{\circ}\right)$ compared with the untreated, annealed and freeze dried films (Figure 3a). The composite film showed light domains surrounded by darker areas (Figure 2d). The light domains are probably composed of active carbon-rich phases, while the dark areas can be attributed to the polymer phase. These differences are highlighted in Figure 1, which shows cross-sections of each of the AFM images. For the composite film, the difference in height between the light and dark areas is apparent $(\sim 15 \mathrm{~nm})$, as are the lengths of the light domains $(\sim 2 \mu \mathrm{m})$, while the other films are much more homogeneous, with negligible differences being seen in height profiles. The rms roughness value of the composite film is about $2.54 \mathrm{~nm}$ (Figures $2 \mathrm{~d}$ and $3 \mathrm{~b}$ ). The presence of active carbon in the composite film may have increased surface roughness. The increase in surface roughness reflected in the increase in hydrophobicity. 
(c)

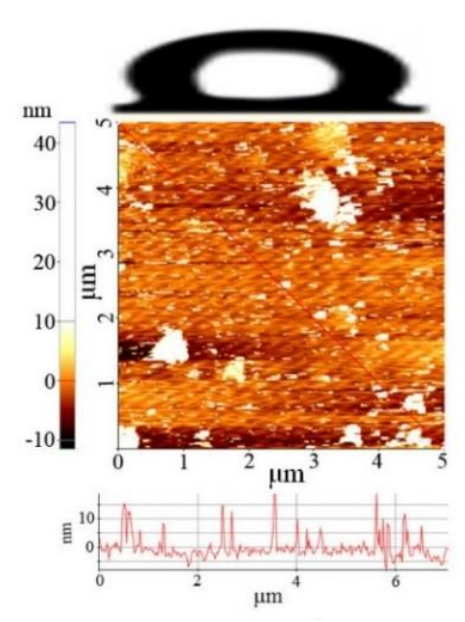

(a)

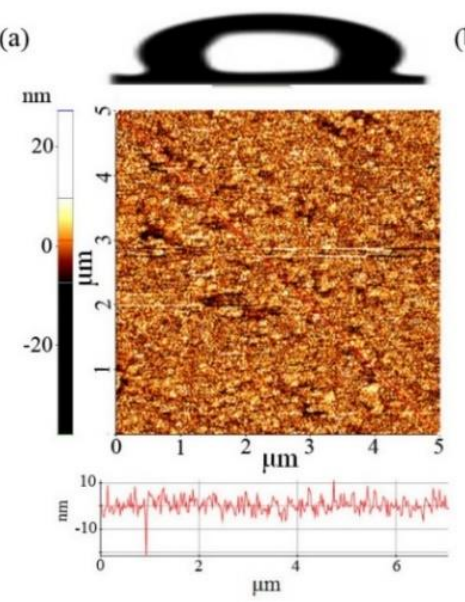

(d)
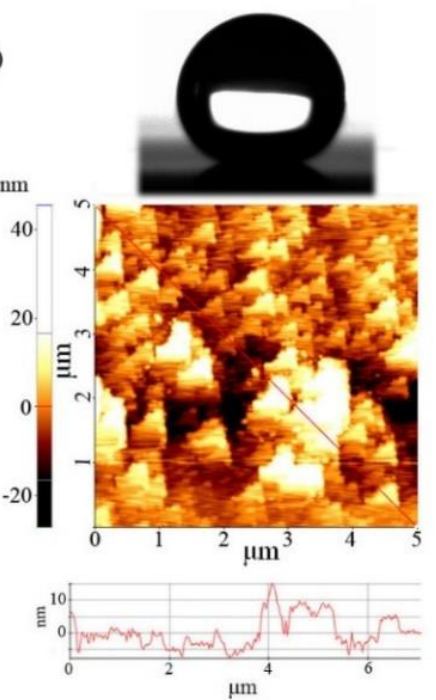

(b)

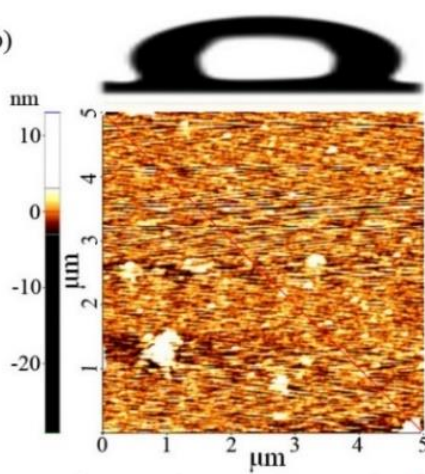

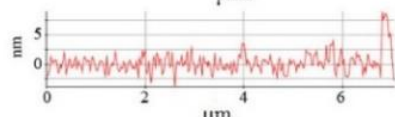

Figure 2. AFM images (bottom) and photographs of $4 \mu \mathrm{L}$ water droplets (top) on PHFDA films (a) untreated, (b) annealed, (c) freeze-dried and (d) composite films. The cross-sections corresponding to the red line shown in the AFM images are given below each image
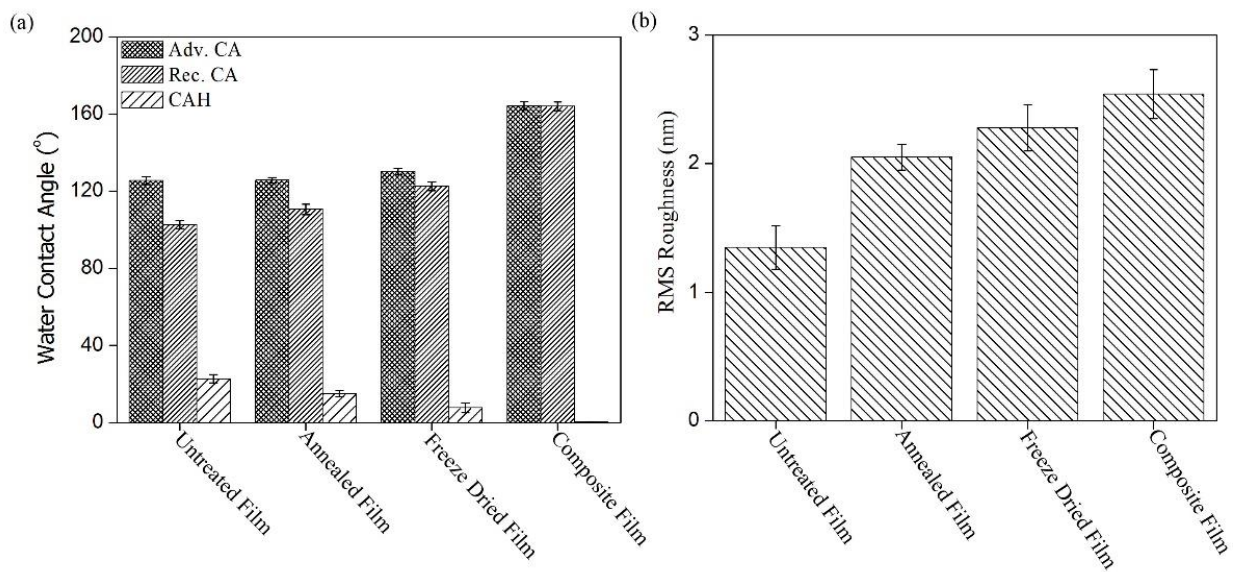

Figure 3. Variation of (a) advancing (Adv.CA), receding (Rec.CA) water contact angle and hysteresis $(\mathrm{CAH})$, and (b) rms roughness values of untreated, annealed, freeze-dried and composite films

As a conclusion, we created superhydrophobic surfaces using simple processes such as annealing at $120^{\circ} \mathrm{C}$, freeze-drying at $-40^{\circ} \mathrm{C}$ and forming composites. Among them, the composite film composed of PHFDA and active carbon exhibited the highest hydrophobicity $\left(\theta_{\mathrm{A}} / \theta_{\mathrm{R}}=165^{\circ} / 164^{\circ}\right)$. In 
conclusion, the addition of superhydrophobicity by the formation of composite film to the well known antifouling properties of the fluoropolymers may lead to new coating applications.

\section{ORCID}

Mehtap Evci: 0000-0003-3451-6462

Tuncer Caykara: $\underline{0000-0002-4882-8515}$

\section{References}

[1] Barthlott, W.; Neinhuis, C. Purity of the sacred lotus, or escape from contamination in biological surfaces. Planta 1997, 202(1), 1-8.

[2] Neinhuis, C.; Barthlott, W. Seasonal changes of leaf surface contamination in beech, oak, and ginkgo in relation to leaf micromorphology and wettability. New Phytol. 1998, 138(1), 91-98.

[3] Feng, L.; Li, S.; Li, Y.; Li, H.; Zhang, L.; Zhai, J.; Zhu, D. Super-hydrophobic surfaces: from natural to artificial. Adv. Mater. 2002, 14(24), 1857-1860.

[4] Veeramasuneni, S.; Drelich, J.; Miller, J. D.; Yamauchi, G. Hydrophobicity of ion-plated PTFE coatings. Progr. Org. Coat. 1997, 31(3), 265-270.

[5] Chen, W.; Fadeev, A. Y.; Hsieh, M. C.; Öner, D.; Youngblood, J.; McCarthy, T. J. Ultrahydrophobic and ultralyophobic surfaces: some comments and examples. Langmuir 1999, 15(10), 3395-3399.

[6] Nishino, T.; Meguro, M.; Nakamae, K.; Matsushita, M.; Ueda, Y. The lowest surface free energy based on$\mathrm{CF}_{3}$ alignment. Langmuir 1999, 15(13), 4321-4323.

[7] Coulson, S. R.; Woodward, I.; Badyal, J. P. S.; Brewer, S. A.; Willis, C. Super-repellent composite fluoropolymer surfaces. J.Phys. Chem. B 2000, 104(37), 8836-8840.

[8] Wu, S. H. Polymer interface and adhesion, M. Dekker, New York, 1982.

[9] Shang, H. M.; Wang, Y.; Takahashi, K.; Cao, G. Z.; Li, D.; Xia, Y. N. Nanostructured superhydrophobic surfaces. J. Mater. Sci. 2005, 40(13), 3587-3591.

[10] Zhong, Y.; Gu, L.; Wang, S.; Jin, Y. and Xiao, H. Green and superhydrophobic coatings based on tailormodified lignocellulose nanofibrils for self-cleaning surfaces. Ind. Eng. Chem. Res. 2019. https://doi.org/10.1021/acs.iecr.9b04279.

[11] Wang, N.; Wang, Q.; Xu, S. and Zheng, X. Eco-friendly and safe method of fabricating superhydrophobic surfaces on stainless steel substrates. J.Phys.Chem. C 2019, 123(42), 25738-25746

[12] Tu, K.; Wang, T.; Kong, L.; Guan, H. Facile preparation of mechanically durable, self-healing and multifunctional superhydrophobic surfaces on solid wood. Mater. Design 2018, 140, 30-36.

[13] Park, J. B.; Choi, W. S.; Chung, T. H.; Lee, S. H.; Kwak, M. K.; Ha, J. S.; Jeong, T. Transfer printing of vertical-type microscale light-emitting diode array onto flexible substrate using biomimetic stamp. Opt. Express 2019, 27(5), 6832-6841.

[14] Lee, D.; Seo, S. B.; Kim, D. Y.; Kim, H. M.; Cho, C.; Lee, J., Kim, B. Nanotextured and polytetrafluoroethylene-coated superhydrophobic surface. Thin Solid Film. 2013, 547, 111-115.

[15] Ozturk, T.; Erbil, H. Y. Evaporation of water-ethanol binary sessile drop on fluoropolymer surfaces: Influence of relative humidity. Colloid. Surf. A: Physicochem. Eng. Asp. 2018, 553, 327-336.

[16] Erbil, H. Y.; Demirel, A. L.; Avc1, Y.; Mert, O. Transformation of a simple plastic into a superhydrophobic surface. Science 2003, 299(5611), 1377-1380.

[17] Söz, C. K.; Yilgör, E.; Yilgör, I. Influence of the average surface roughness on the formation of superhydrophobic polymer surfaces through spin-coating with hydrophobic fumed silica. Polymer 2015, 62, 118-128.

[18] Izunobi, J. U.; Higginbotham, C. L. Polymer molecular weight analysis by ${ }^{1}$ H NMR spectroscopy. J. Chem. Educ. 2011, 88(8), 1098-1104.

[19] Tan, K. L.; Woon, L. L.; Wong, H. K.; Kang, E. T.; Neoh, K. G. Surface modification of plasma-pretreated poly (tetrafluoroethylene) films by graft copolymerization. Macromolecules 1993, 26(11), 2832-2836.

[20] Yamaguchi, H.; Honda, K.; Kobayashi, M.; Morita, M.; Masunaga, H.; Sakata, O.; Takahara, A. Molecular aggregation state of surface-grafted poly $\{2$-(perfluorooctyl) ethyl acrylate $\}$ thin film analyzed by grazing incidence X-ray diffraction. Polymer J. 2008, 40(9), 854.

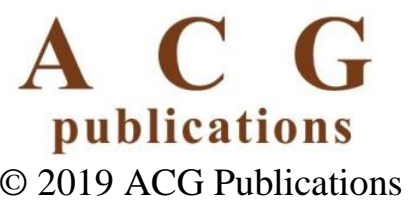

